\title{
Personality and psychological conditions in relation to job engagement amongst municipal workers in the Eastern Cape province, South Africa
}

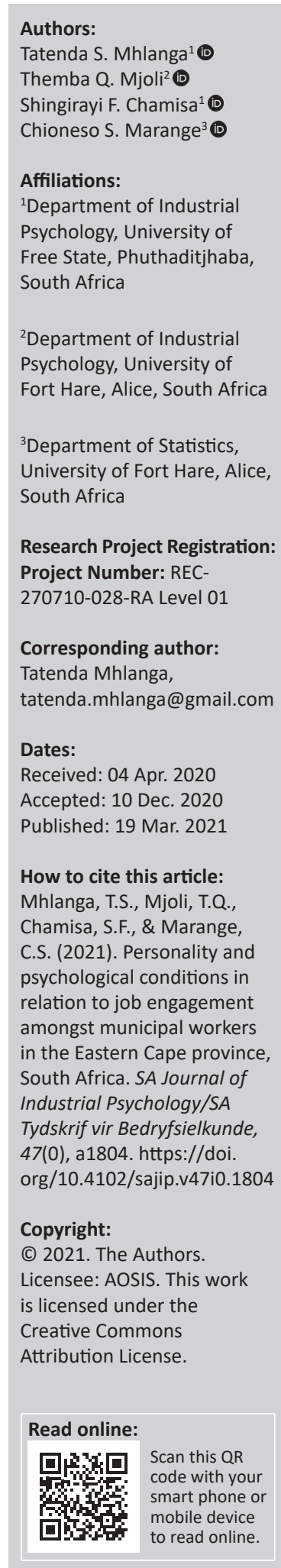

Orientation: Increasing job engagement in a sustainable way remains a challenge and the question remains as to why employees, when working under comparable conditions display signs of job engagement whereas others display a few or no signs of job engagement.

Research purpose: The aim of the study was to investigate the linear relationships and establish usable models for the big five personality traits and psychological conditions on job engagement amongst municipal workers.

Motivation for the study: The motivation of this study is to examine the relationship between personality and psychological conditions on job engagement.

Research approach/design and method: The study employed a quantitative, cross- sectional research design using a questionnaire on a sample of 403 district municipal workers in the Eastern Cape province, South Africa.

Main findings: Findings show that conscientiousness, extraversion, agreeableness, intellect and all psychological conditions had a positive relationship with job engagement while neuroticism has a negative relationship with job engagement. Hierarchical regression models revealed that psychological conditions add unique variance in predicting job engagement above and beyond that which is predicted by the personality traits.

Practical/managerial implications: Job engagement can be enhanced through the hiring employees with certain personality traits and enhancing meaningfulness, safety and availability of psychological resources in the workplace.

Contribution/value-add: The study findings support a relatively rich literature which suggests that employees with certain personality traits such as conscientiousness, agreeableness, intellect and perceives that all psychological conditions are being met tend to be more engaged in their job.

Keywords: personality; job engagement; psychological conditions; municipal workers; Eastern Cape.

\section{Introduction}

The Fourth Industrial Revolution has led many organisations to continuously search for ways to tap into the ever-changing world of work. The desire to maximise human capital is not a new concept; the methods used are changing to reflect the important role job engagement plays in the workplace. Job engagement has been considered as the most popular topic to be incorporated within the human resource management agenda if organisations are to outmanoeuver their competitors. According to Chen and Nadkarni (2017), because of intensive global competition there is need for organisations to better utilise human resources to achieve success. Nienaber and Martins (2016) conceived competitive advantage as the hallmark of rigorous strategy. Therefore, for organisations to successfully increase their competitive advantage, they need to develop strategies to attract, motivate and retain a highly skilled, flexible and adaptive workforce. These strategies are within the human resource management practises and can be addressed with factors such as job engagement, psychological conditions and personality traits. Despite the popularity of the concepts within the organisational setting, research findings on the potential of these constructs to attract, motivate and retain talent are not consistent. Mixed results have been reported on the impact of personality and psychological conditions on job engagement (Gulamali, 2017; Ongore, 2014). Conducting more research on the concepts using different populations and organisation will provide an indication on the empirical estimation of the constructs to achieve 
desired outcomes, such as attraction and motivation of talent in the organisation. Most of the contemporary literature focuses on the private sector (Jansriboot, 2016; Ziapour \& Kianipour, 2015) and this study focused on the public sector. Most studies carried out on job engagement and personality have recommended that researches need to be performed with other samples for further studies to compare the results (De Villiers, 2015; Hale, 2016).

Municipalities' workers are faced with low job engagement and this has affected service delivery, which is crucial to the sustainability of citizens (Njomo, 2019). The efficiency of service delivery depends on the public employees' performance. The Eastern Cape province has gained so much criticism because of its poor service delivery (Matebesi \& Botes, 2017). Findings from this study provide an empirical estimation of how an organisation can achieve the desired organisational goals. Organisational leaders who effectively engage employees could reduce employees' intention to leave and improve productivity (Njomo, 2019).

Currently, practitioners and academics have paid increasing attention to employees' job engagement (Bailey, Madden, Alfes, \& Fletcher, 2017; Eldor \& Harpaz, 2016). Job engagement had been found to be important in the academic world specifically in industrial-organisational psychology as it is linked to desirable results such as high performance, productivity, profitability and good well-being (Rothmann, 2017). Job engagement was initially proposed as a positive construct (Kahn, 1990), and empirical studies revealed that a high level of job engagement leads to positive work outcomes (Shkoler \& Kimura, 2020). Recent studies have acknowledged that engaged employees boost profitability by being productive and this increases an organisations' competitive advantage (Barreiro \& Treglown, 2020; Werner, 2014). Engagement will likely become central to all future tasks, decisions and processes related to human resources as employees are key to business success, however, increasing job engagement in a sustainable way has remained a challenge regardless of years of exploration (Rothmann, 2017). Hence, it is crucial to understand why other employees are engaged in their tasks, which leads to further investigation on the process that triggers engagement.

The research on the dispositional antecedents of engagement is unclear about the influences of personality traits. According to Woods and Sofat (2013), future studies could use more detailed measures of personality that enable a more in-depth examination of which traits of personality are key for engagement. In addition, according to Akhtar, Boustani, Tsivrikos and Chamorro-Premuzic (2015), future analyses should also examine the relationships between its different dimensions and personality to detect potential differences. This study focused on the big five personality traits and Kahn's three job engagement dimensions.

Given that job engagement is linked with discernible personality features such as conscientiousness and agreeableness (Mat, Jansriboot, \& Mat, 2019) and with certain job characteristics such as feedback, autonomy and task identity (Bayoumy, 2019), it is imperative to consider their possible mode of combination. This study looked at psychological conditions and personality traits and their relationship to job engagement. Kahn (1990) conceptualised engagement as an individual extension through the psychological conditions of meaningfulness, safety and availability to a work role. These psychological conditions affect personal engagement and disengagement at work (Kahn \& Heaphy, 2014). According to Asiwe (2014), researchers could hardly find any literature on South African studies that included psychological safety. Most of the studies have focused on job engagement and the mediational effect of psychological meaningfulness and availability (Chikoko, Buitendach, \& Kanengoni, 2014). There is very little knowledge about the relationship between job engagement and psychological safety (Bailey et al., 2017; Zehr, 2017), and the literature is even more scant relative to results associated with the public workers in South Africa. In addition, Frazier, Fainshmidt, Klinger, Pezeshkan and Vracheva (2017) identified the examination of employee engagement as an antecedent of psychological safety with both having the ability to influence each other positively as an important area for future research with relevance to researchers from both communities.

\section{Problem statement}

Employees who demonstrate separation or disengagement in work have low performance levels and show no commitment to perform well (Imam \& Shafique, 2014). Previous research has reported a strong positive relationship between engagement and job performance (Aon Hewitt, 2018; Van den Berg, Mastenbroek, Scheepers \& Jaarsma, 2017). In a longitudinal study done by Carter, Nesbit, Badham, Parker and Sung (2018), within an Australian financial services firm, job engagement explained $12 \%$ of appointments made and $39 \%$ of products sold over and above that explained by past performance. Schwartz (2012) indicated that organisations with low employee engagement actually lose $33 \%$ of their annual operating income as compared with $11 \%$ annual loss in earnings growth. In addition, organisations with high employee engagement estimate an increase of $19 \%$ of their operating income and $28 \%$ annual growth in earnings. These organisations tend to have lower employee turnover, higher productivity and higher total shareholder returns (Mourino-Ruiz, 2017).

According to the Public Display Technologies 2014 State of Employee Engagement survey amongst public workers, almost one in five workers are less engaged in their work (Public Display Technologies Report, 2014). Municipalities have faced many challenges including poor service delivery, insolvency and delays in project implementation, which led to a lack of trust and confidence by the public. According to Deloitte Consulting (2014), in a study that was conducted in Africa on employee engagement and retention about $85 \%$ of the respondents indicated that this was a matter that needs to be dealt with urgently, whilst $29 \%$ were simply not ready to 
face the issue. Nearly $63 \%$ of the respondents regarded employee engagement as the second most imperative challenge for South Africa. In addition, Crabtree (2013) stated that in South Africa, only $9 \%$ of workers are engaged. It therefore, seems appropriate to conduct a study of job engagement amongst municipal employees as the alleged lack of service delivery may be largely because of a lack of job engagement amongst these employees.

\section{Objectives of the study}

The main objective of the study was to examine how the Big Five personality traits and psychological conditions relate to job engagement. It also seeks to examine if psychological conditions add unique variance in predicting job engagement over and above individual personality traits.

\section{Literature review}

\section{Theoretical perspective}

\section{The job demand resources model}

This model was established by Demerouti, Bakker, De Jonge, Janssen and Schaufeli (2001) and it adopts that job engagement results from innately motivating nature of job resources and demands. Job resources are those work aspects that are useful in accomplishing work objectives, decrease job demands or invigorate individual development and advancement. Job demands are job features that demand continuous psychological exertion or abilities such as work pressure and emotional demands. The job demands-resources model suggests that when employees are granted increased resources, they are more prone to be engaged (Bailey et al., 2017) and the provision of additional resources can serve as mitigation to the stress-related effects on the employee (Bakker \& Demerouti, 2017).

This has been reinforced by the suggestion that workforces with extreme job demands and inadequate resources are expected to undergo burnout thereby experiencing a decrease in engagement, respectively (Hakanen, Bakker, \& Schaufeli, 2006). This theory is applicable to this study as it provides a link of the relationship between job resources (job and personal) and work engagement. Employees are more involved in their job if they have adequate resources (meaningful work, safety and availability psychological conditions) and personal resources such as personality to deal with the demands of their job.

\section{Conceptual literature review}

\section{Job engagement}

The world of work is constantly changing hence organisations need to maximise the contributions of their workers by ensuring that employees are emotionally and cognitively dedicated to their job and the organisation (Rothmann, 2017). There is an emerging and ongoing focus on employees being engaged in their organisations (Abu Khalifeh \& Som, 2013). The construct has been labelled with different names, for instance, the construct was called 'work engagement' (refers to individuals' relationships with their actual work, Schaufeli, Salanova, Gonzalez-Roma, \& Bakker, 2002), 'job engagement' (Rich, Lepine, \& Crawford, 2010) and 'employee engagement' (Macey \& Schneider, 2008). The terms job engagement and work engagement have been used interchangeably to refer to the relationship between the employee and their work (Rich et al., 2010; Schaufeli, 2013).

In terms of work engagement, most studies used the Utrecht Work Engagement Scale (UWES) questionnaire and focus on absorption, vigour and dedication. Their definitions of job engagement are mainly based on the burnout approach which is based on Schaufeli et al.'s (2002) definition of engagement which is 'a positive, fulfilling, work related state of mind that is characterised by vigour, dedication and absorption' (p. 74). Vigour refers to high levels of energy and mental resilience whilst working, dedication refers to being strongly involved in one's work and absorption refers to being fully concentrated and happily engrossed in one's work. On the other hand, this study focused on Kahn's view on job engagement and three dimensions of physical, emotional and cognitive engagement (CE) (Kahn, 1990). This study utilised Kahn's (1990) definition of engagement which defines engagement as 'the harnessing of organization members' selves to their work roles: in engagement, people employ and express themselves physically, cognitively, emotionally and mentally during role performances' (p. 694). Both academic conceptualisations agree that engagement entails a physical-energetic (vigour), an emotional (dedication) and a cognitive (absorption) component. It appeared particularly that the CE and absorption scales are strongly related, whereas the physical engagement (PE) and the vigour scales are only weakly related, with the emotional engagement (EE) and dedication scales somewhere in between (Viljevac, Cooper-Thomas, \& Saks, 2012). Also, Schaufeli et al. (2002) have since noted that engagement is not quite the exact opposite of burnout, but the UWES retains the fundamental scale structure.

According to Khan, engagement mirrors the concurrent investment of cognitive, emotional and physical efforts to provide full execution of a task (Rich et al., 2010):

- Physical engagement: Physical engagement is experienced when an employee exerts physical energies to achieve a task from stupor to energetic participation (Rich, 2006).

- Emotional engagement: Rich (2006) gave a summary of EE according to Kahn's (1990) concept as a positive sentimental respond to an individual's job.

- Cognitive engagement: Rich (2006) gave a summary of CE according to Kahn's (1990) concept as consideration of an assimilation in an individual's job. On the other hand, cognitive disengagement simply means the absence of concentration towards one's job (Rich, 2006).

\section{Personality}

According to the American Psychological Association, personality comprises of an individual's relatively constant 
feelings, thoughts and behavioural patterns (APA, 2017). Choudhry and Zafar (2017) pointed out that personality traits signify the most significant qualities that mould the social landscape of individuals. Studying personality within an employee's conduct and outlook assist in envisaging authentic behavioural intents (Sahi \& Mahajan, 2014). The study looked at the big five personality traits, which are as follows:

- Neuroticism: It refers to individuals who frequently experience feelings of guilt, grief, fruitlessness, anxiety and tautness and are passionately unpredictable and are effortlessly angered and insecure (Lebowitz, 2016). Individuals with high neuroticism are also unbalanced versus emotional stability that typifies individuals as being self-assured and steady (Goldberg, 1992; McCrae \& John, 1992).

- Extraversion: According to Lebowitz (2016) positive emotionality, sociability, boldness and experience seeking are the underlying extraversion facets. This dimension measures your level of sociability (Goldberg, 1992).

- Intellect: According to Judge, Higgins, Thoresen and Barrick (1999) intellect is characterised by intellectance (philosophical and intellectual) and unconventionality (imaginative, autonomous and nonconforming). Other researchers refer to intellect as openness to experience which is the tendency to fantasise, know about one's feelings, fondness for originality, intellectual inquisitiveness and being generous in principles (Costa \& McCrae, 1992).

- Agreeableness: People high in agreeableness are compassionate, affectionate and sympathetic to strangers' predicaments and have few opponents (Lebowitz, 2016). According to Goldberg (1992) this dimension measures how well you get on with other people.

- Conscientiousness: Conscientiousness makes individuals to have socially impulse management that assists employees to accomplish their jobs effortlessly (Costantini et al., 2015). These individuals are reliable and selfdisciplined (Goldberg, 1993).

\section{Psychological conditions}

Kahn (1990) contemplated how individuals' encounters of themselves and their work setting impacted on personal engagement and disengagement. He contended that individuals pose three principal inquiries in every part circumstance: (1) How meaningful is it for me to bring myself to this performance? (2) How safe is it to do? (3) How available am I to do such? As indicated by Kahn (1990), these three psychological conditions affect employees' engagement as employees can engage at the workplace only when the three conditions are jointly achieved (Shuck \& Reio, 2013):

- Psychological meaningfulness: Meaningfulness implies feelings of being worthwhile, valuable and having usefulness and feelings that they are appreciated (Kahn \& Heaphy, 2014).

- Psychological safety: Safety was defined as the capability to demonstrate one's self without fear or negative consequences to self-image, status or career (Kahn, 1990).
- Psychological availability: Kahn characterised availability as the feeling of having the physical, emotional and psychological recourses essential to accomplish a task at that moment (Kahn, 1990).

\section{Empirical literature review}

Pocnet et al. (2015) explored the links between personality traits, demographic characteristics and work engagement. Work engagement was negatively associated with neuroticism and positively associated with extraversion, openness, conscientiousness and agreeableness traits. Similarly, Handa and Gulati (2014) found that there is a positive relationship between extraversion and conscientiousness personality traits and employee engagement. In a cross-sectional research carried out by Muizu (2017), personality significantly influenced employee engagement. This study is similar to the study carried out by by Ziapour and Kianipour (2015) who reported that there were important connections between the two dimensions of personality traits, which are neuroticism and extraversion and job engagement whilst the outcomes of multiple regression analysis revealed that dutifulness and agreeableness were good predictors for job engagement. In a study carried out by Moshoeu (2017), the results revealed significant relationships between the variables such as agreeableness, conscientiousness and emotional stability, which in turn significantly and positively predicted employee engagement. Psychological meaningfulness and psychological availability had direct effects on employee engagement (Rothmann \& Baumann, 2014).

\section{Research design Research approach}

In the present research, the quantitative survey research design was used, which is based on seeking the objective truth of whether there is a relationship that is scientific in nature (Sekaran \& Bougie, 2013). A cross-sectional quantitative research design was followed in order to achieve the study objectives.

\section{Research method}

\section{Research participants}

The target population of the study comprised of all the municipal workers from six district municipalities in the province of Eastern Cape, which are, Alfred Nzo District Municipality, Cacadu District Municipality, Chris Hani District Municipality, Amathole District Municipality, Joe Gqabi District Municipality and O.R. Tambo District Municipality. A total of 403 municipal employees from a population of 29000 participated in the study. Convenience sampling was used primarily based on their availability and willingness to participate in the study.

\section{Measuring instruments}

The data were collected using a questionnaire that consisted of four sections as discussed here including demographic 
information such as race, gender, marital status, age, tenure, occupational level and educational level.

\section{Job engagement scale}

The 18-item job engagement scale (JES) developed by Rich et al. (2010) was used. The scale is based on Kahn's conceptualisation of engagement. Employees were requested to indicate their level of agreement with statements on how they are engaged with their jobs (e.g. I strive as hard as I can to complete my job) on a 5-point Likert-type scale ranging from 'strongly disagree' (1) to 'strongly agree' (5). Ongore (2014) reported internal consistency coefficient for the PE dimension as $\alpha=0.91, \alpha=0.94$ for EE and $\alpha=0.95$ for CE.

\section{Big five markers}

The personality traits were measured using the 50-item International Personality Item Pool (IPIP) Big Five Markers (Goldberg et al., 2006). Every trait was measured by 10 items. Each item is a phrase describing behaviour (e.g. 'I am the life of the party'), and participants were instructed to indicate how accurate this phrase is for them, using a 5-point Likert-type scale ( 1 , very inaccurate and 5 , very accurate). The traits were found to have the following alpha coefficients: conscientiousness (0.79), extraversion (0.87), agreeableness (0.82), intellect (0.84) and neuroticism (0.86) (Goldberg et al., 2006). Lim and Ployhart (2006) examined the construct, convergent and discriminant validity of the Big Five Markers by comparing it with the Neuroticism-Extraversion-Openness Five-Factor Inventory (NEO-FFI) personality model and found that the scale presents a good fit for the five-factor model. According to Reddy (2012) Goldberg's Big-Five Factor Markers in the South African context showed somewhat satisfactory reliability for research purposes and the results also suggested that Goldberg's BigFive Factor Markers is an assessment that has some potential in the South African context.

\section{Psychological conditions}

Psychological conditions consisted of three constructs namely, psychological meaningfulness, psychological safety and psychological availability. A survey developed by May, Gilson and Harter (2004) was used to test these constructs. Psychological meaningfulness consists of six items to assess the degree of meaning that individuals perceive in their work-related activities. On the other hand, psychological safety consists of three-items, which measures the psychological perceptions of safety whilst psychological availability uses a five-item scale to measure the confidence that individuals have regarding their ability to be physically, cognitively and emotionally available for work. The items for these constructs were scored on a 7-point Likert scale ranging from one (strongly disagree) to seven (strongly agree). Chikoko et al. (2014) reported internal consistency coefficient for psychological meaningfulness as $\alpha=0.91$, $\alpha=0.81$ for psychological availability and $\alpha=0.6$ for psychological safety. The reliability and subsequent validity of these measures were reinforced in another study by Olivier and Rothmann (2007).

\section{Research procedure}

Questionnaires together with blank envelopes were given to the respondents. Questionnaires included a cover page with instructions to the participants and information on the assessments, research and contact details of the researcher for any clarification required. The consent form was also included in the questionnaire and which participants were requested to sign. Participants were given 1 week to complete and return them. Confidentiality was ensured as the respondents had envelope to seal in their responses and no personal identifying information was required. The sealed responses were kept at the HR Department.

\section{Statistical analysis}

Statistical Package for Social Sciences (SPSS) version 25 was used for analysis (IBM Corp, 2017). A descriptive analysis was used to describe the study's demographic features and the main theoretical variables. The Pearson correlation coefficients were utilised to determine whether personality traits and psychological conditions have any significant relationship with job engagement. Lastly, to examine if the psychological conditions add unique variance in predicting job engagement above and beyond that which is predicted by the personality traits, hierarchical multiple linear regression models were used. Tests for normality were carried out using the normal plots of the standardised residuals. Accessing these plots, it was found that the points of the expected against the observed cumulative probabilities were lying on the line, hence the normality assumption for linear regression modelling was satisfied.

\section{Results \\ Demographic information}

A total of 403 samples were used. The respondents of the study were mostly male employees $(n=210,52.1 \%)$ and $74.9 \%(n=302)$ were Black African. Most of the respondents were in the age group of $31-40$ years $(n=136,33.7 \%)$ and $44.4 \%(n=179)$ of the respondents were single in terms of their marital status whilst $36.2 \%(n=146)$ were classified as married. A Diploma $(n=107 ; 26.6 \%)$ was the most frequently reported qualification followed by a Degree $(n=97,24.1 \%)$. In terms of occupational level, the majority of the respondents ( $n=192,47.6 \%)$ worked on level 6-10 salary level in the municipality and most of them have been working in the municipality for $1-5$ years $(n=174,43.2 \%)$. Almost $70 \%$ $(n=219)$ of the employees were permanently employed.

\section{Reliability and descriptive analysis}

Cronbach's alpha was adopted to measure the instrument's internal consistency (see Table 1). The Cronbach's alpha coefficient for the JES and its respective constructs ranged from $\alpha=0.83$ to $\alpha=0.93$ showing high reliability for these variables. As for personality traits, conscientiousness $(\alpha=0.74)$, extraversion $(\alpha=0.74)$, neuroticism $(\alpha=0.78)$, intellect $(\alpha=0.76)$ and agreeableness $(\alpha=0.73)$ were all reliable. The Cronbach's alpha coefficient for all the constructs for psychological 
conditions $(\alpha=0.86)$ were ranging from 0.76 to 0.90 , which also shows high levels of reliability. According to Nunnally and Bernstein (1994) Cronbach's alpha of 0.7 and higher are satisfactory.

Table 1 also shows the descriptive statistics of the main study variables. The findings reveal moderately high mean levels for overall job engagement $(M=4.07$, s.d. $=0.69)$ and its respective constructs. There were moderate levels for the various personality traits, thus conscientiousness $(M=3.57$, s.d. $=0.57)$, extraversion $(M=3.17$, s.d. $=0.55)$, agreeableness $(M=3.58$, s.d. $=0.54)$ and intellect $(M=3.43$, s.d. $=0.50)$. Neuroticism $(M=2.85$, s.d. $=0.70)$ recorded a somewhat low mean level for the study sample. On the other hand, the mean level of psychological conditions $(M=5.44$, s.d. $=0.97)$ was moderately high. This was a similar case for the respective constructs of psychological conditions, which also reported moderately high mean levels. Lastly, the skewness and kurtosis coefficients are evident that the respective variables and theoretical constructs are not consistent with a normal distribution.

\section{Correlation analysis}

Firstly, we conducted a correlational analysis in order to assess the existing relationships between our independent variables (personality traits and psychological conditions and its respective constructs) with the dependent variable (job engagement and the associated constructs). A twotailed Pearson correlation test was opted because of the composite null hypothesis that there is no significant relationship between 'independent variable' and 'dependent variable/independent variable'. Tables 2-4 show the results of the Pearson correlation coefficients $(r)$ for relations of the various hypothesised frameworks. Effect size was used to decide on the practical significance of the findings. According to the basic rules of thumb by Cohen $(1988,1992)$, the effect size is low if the value of the correlation coefficient varies around the absolute value of 0.1 , medium if it varies around 0.3 and large if it varies more than 0.5 . Thus, the correlation coefficient itself is interpretable as an effect size measure.
Table 2 shows that job engagement had moderate, positive and significant relationships with agreeableness $(r=0.389)$ and conscientiousness $(r=0.402)$ whilst having somewhat moderate, positive and significant correlation with intellect $(r=0.351)$. These findings reveal medium effect sizes for the established relationships. On the other hand, extraversion had a weak, positive and significant relationship with job engagement $(r=$ 0.119) whilst neuroticism had a weak, negative significant relationship with job engagement $(r=-0.122)$. According to Cohen $(1988,1992)$, the effect size of these relationships is regarded as low. Conscientiousness, intellect and agreeableness all had moderate, significant and positive correlations with all the three job engagement dimensions. The effect size of these relationships also suggest a medium effect (all $0.351<r<0.402$ ). Neuroticism had significant and weak, negative correlation with physical $(r=-0.110)$ and emotional $(r=-0.140)$ engagement suggesting a low effect size. However, the study finds no significant correlation between neuroticism and CE $(r=-0.091)$.

Table 3 shows the findings of the Pearson correlation analysis for relations of psychological conditions and job engagement. Job engagement had a moderate, positive and significant correlation with meaningfulness $(r=0.571)$, availability $(r=0.525)$ and psychological conditions as a whole $(r=0.618)$. Similar moderate, positive and significant relationships also existed between the various constructs of job engagement with meaningfulness, availability and psychological conditions. The practical significance of these established correlation coefficients (with $r$ around 0.5) represents a large effect size. However, on the other hand safety had a positive significant but somewhat weak correlation with job engagement $(r=0.257)$. A similar trend in correlational significance, strength and direction existed between safety and PE $(r=0.237)$ and with EE $(r=0.257)$. A weaker, positive and significant relation existed between safety and CE $(r=0.191)$. According to Cohen (1988), the effect size of the relationship of psychological safety with job engagement is regarded as somewhat medium effect.

In Table 4 there is a sufficient evidence at $1 \%$ level of significance to conclude that there exists moderate, positive

TABLE 1: Summary of descriptive statistics of main variables and reliability analysis using the Cronbach's alpha coefficient.

\begin{tabular}{|c|c|c|c|c|c|c|c|c|}
\hline Variable & Minimum & Maximum & Mean & SD & Skewness & Kurtosis & Items used & Cronbach's alpha $\alpha$ \\
\hline Job engagement & 1.06 & 5.00 & 4.07 & 0.69 & -0.79 & 0.98 & 18 & 0.93 \\
\hline Physical & 1.00 & 5.00 & 4.11 & 0.73 & -0.84 & 0.75 & 6 & 0.83 \\
\hline Emotional & 1.00 & 5.00 & 4.06 & 0.80 & -0.85 & 0.57 & 6 & 0.86 \\
\hline Cognitive & 1.00 & 5.00 & 4.03 & 0.78 & -0.79 & 0.62 & 6 & 0.87 \\
\hline \multicolumn{9}{|l|}{ Personality traits } \\
\hline Conscientiousness & 2.20 & 5.00 & 3.57 & 0.57 & 0.03 & -0.54 & 10 & 0.74 \\
\hline Agreeableness & 2.20 & 5.00 & 3.58 & 0.54 & 0.29 & -0.37 & 10 & 0.78 \\
\hline Intellect & 1.90 & 5.00 & 3.43 & 0.50 & -0.08 & -0.09 & 10 & 0.76 \\
\hline Neuroticism & 1.00 & 4.50 & 2.85 & 0.70 & -0.36 & -0.33 & 10 & 0.73 \\
\hline Psychological-conditions & 2.57 & 7.00 & 5.44 & 0.97 & -0.57 & -0.48 & 15 & 0.86 \\
\hline Meaningfulness & 1.00 & 7.00 & 5.65 & 1.22 & -1.10 & 0.82 & 7 & 0.90 \\
\hline Safety & 1.00 & 7.00 & 4.66 & 1.35 & 0.16 & -0.92 & 3 & 0.76 \\
\hline Availability & 1.80 & 7.00 & 5.65 & 1.19 & -0.92 & 0.43 & 5 & 0.87 \\
\hline
\end{tabular}

SD, standard deviation. 
TABLE 2: Pearson correlation coefficients $(r)$ for relations of personality traits and job engagement. Personality traits

\begin{tabular}{|c|c|c|c|c|}
\hline & \multirow{2}{*}{ Physical engagement } & \multirow{2}{*}{ Emotional engagement } & \multirow{2}{*}{ Cognitive engagement } & \multirow{2}{*}{ Job engagement } \\
\hline & & & & \\
\hline Conscientiousness & $0.389 * *$ & $0.355^{* *}$ & $0.332 * *$ & $0.402 * *$ \\
\hline Extraversion & $0.104 *$ & $0.121 *$ & $0.109 *$ & $0.119^{*}$ \\
\hline Agreeableness & $0.374 * *$ & $0.324 * *$ & $0.344 * *$ & $0.389 * *$ \\
\hline Intellect & $0.308 * *$ & $0.315 * *$ & $0.313 * *$ & $0.351 * *$ \\
\hline Neuroticism & $-0.110 *$ & $-0.140 * *$ & -0.091 & $-0.122 *$ \\
\hline
\end{tabular}

$r$, Pearson correlation coefficient.

$*$, Correlation is significant at the 0.05 level (2-tailed); **, Correlation is significant at the 0.01 level (2-tailed).

TABLE 3: Pearson correlation coefficients $(r)$ for relations of psychological conditions and job engagement. Psychological conditions variables

\begin{tabular}{lccc} 
& Physical engagement & Emotional engagement & Cognitive engagement \\
\cline { 2 - 4 } Psych meaningfulness & $0.506^{* *}$ & $0.507^{* *}$ & $0.512^{* *}$ \\
Psych safety & $0.237^{* *}$ & $0.257^{* *}$ & $0.191^{* *}$ \\
Psych availability & $0.456^{* *}$ & $0.449^{* *}$ & $0.257^{* *}$ \\
Psych conditions (whole) & $0.546^{* *}$ & $0.550^{* *}$ & $0.498^{* *}$ \\
\hline
\end{tabular}

$r$, Pearson correlation coefficient.

**, Correlation is significant at the 0.01 level (2-tailed)

and significant correlation between psychological conditions with conscientiousness $(r=0.503)$, agreeableness $(r=0.493)$ and intellect $(r=0.457)$ all suggesting a large effect size. On the other hand, extraversion was found to have a weak, significant and positive correlation with psychological conditions $(r=0.147)$ whilst neuroticism was significantly and negatively correlated with psychological conditions $(r=-0.300)$. This suggests that the practical significance of the established correlation between neuroticism and psychological conditions (with $r$ around the absolute value 0.3 ) represents a medium effect size whilst a low effect exists for the extraversion-psychological conditions relationship (with $r$ around 0.1). However, extraversion did not have a significant relationship with psychological safety.

\section{Inferential analysis using hierarchical multiple regression models}

To examine if the psychological conditions constructs add unique variance in predicting job engagement above and beyond that which is predicted by the personality traits, hierarchical multiple regression models, were used. This section will also address the assessment and establishment of the partial relationship between the independent variables (personality traits and psychological conditions) and the dependent variable (job engagement). The Durbin-Watson test for autocorrelation was used and to test the assumption of homoscedasticity and normality of residuals special Q-Q plots were used. Results of the hierarchical multiple regression analysis are presented in Tables 5-9. Cohen's $f^{2}$ was used as the effect size measure of choice. Basic rules of thumb are that if Cohen's $f^{2}$ is near 0.02 indicates a small effect, near 0.15 indicates a medium effect and above 0.35 indicates a large effect (Cohen, 1988).

Table 5 shows that conscientiousness as the only predictor variable for job engagement explains $16.2 \%$ of the variation in the dependent variable $\left(R^{2}=0.162\right)$. From this significant model, the results of the estimated beta parameters reveal positive significant effect of conscientiousness $\left(\beta_{1}=0.402\right)$ on job engagement. Cohen's $f^{2}$ shows that the effect size measure for the conscientiousness (Cohen's $f^{2}=0.193$ ) only model indicates medium effect on job engagement. Combined with psychological conditions, the resultant model accounted for a total of $40.5 \%$ of the variation in job engagement $\left(R^{2}=0.405\right)$. Thus, this model adds significant amount of variation in explaining job engagement to the first model. This means adding psychological meaningfulness, psychological safety and psychological availability to conscientiousness as independent variables on job engagement results in a significant increase in the amount of variance explained by the model $\left(\Delta R^{2}=0.243\right.$; Sig $\Delta F=$ $<0.0001)$. The estimated beta parameters reveal positive significant effect of conscientiousness $\left(\beta_{1}=0.140\right)$, psychological meaningfulness $\left(\beta_{2}=0.365\right)$ and psychological availability $\left(\beta_{4}=0.237\right)$ on job engagement. Cohen's $f^{2}$ shows that the effect size measure for this resultant model (Cohen's $f^{2}=0.681$ ) indicates large effect on job engagement.

Table 6 shows that extraversion as the only predictor variable for job engagement explains only $1.40 \%$ of the variation in the dependent variable $\left(R^{2}=0.014\right)$. From this model, the results of the estimated beta parameters reveal positive significant effect of extraversion $\left(\beta_{1}=0.119\right)$ on job engagement. Cohen's $f^{2}$ shows that the effect size measure for the extraversion (Cohen's $f^{2}=0.014$ ) only model indicates small effect on job engagement. Combined with psychological conditions, the resultant model accounted for a total of $39.2 \%$ of the variation in job engagement $\left(R^{2}=0.392\right)$. Thus, this model adds significant amount of variation in explaining job engagement to the extraversion only model. This means adding psychological meaningfulness, psychological safety and psychological availability to extraversion as predictor variables on job engagement results in a significant increase in the amount of variation explained by the model $\left(\Delta R^{2}=0.377, \operatorname{Sig} \Delta F=<0.0001\right)$. The estimated 
TABLE 4: Pearson correlation coefficients $(r)$ for relations of personality traits and psychological conditions. Personality traits

\begin{tabular}{lccc} 
& Psychological meaningfulness & Psychological safety & Psychological availability \\
\cline { 2 - 4 } Conscientiousness & $0.390^{* *}$ & $0.373^{* *}$ & $0.409^{* *}$ \\
Extraversion & $0.142^{* *}$ & 0.089 & $0.100^{*}$ \\
Agreeableness & $0.378^{* *}$ & $0.352^{* *}$ & $0.503^{* *}$ \\
Intellect & $0.446^{* *}$ & $0.153^{* *}$ & $0.414 * *$ \\
Neuroticism & $-0.116^{*}$ & $-0.473^{* *}$ & $0.384^{* *}$ \\
\hline
\end{tabular}

$r$, Pearson correlation coefficient.

*, Correlation is significant at the 0.05 level (2-tailed); **, Correlation is significant at the 0.01 level (2-tailed).

TABLE 5: Hierarchical multiple regression analyses testing conscientiousness and psychological conditions constructs in the prediction of job engagement.

\begin{tabular}{|c|c|c|c|c|c|c|c|c|}
\hline \multirow[t]{2}{*}{ Model } & \multirow[t]{2}{*}{ Variable } & \multicolumn{3}{|c|}{$\begin{array}{l}\text { Dependent variable: Job engagement - Parameter } \\
\text { estimates }\end{array}$} & \multicolumn{4}{|c|}{ Model summary } \\
\hline & & Std. beta & $t$ & Sig. & $R^{2}$ & $R^{2} \Delta$ & Cohen's $f^{2}$ & Sig. $F \Delta$ \\
\hline$\dagger$ & Conscientiousness $\dagger$ & 0.402 & 8.789 & 0.000 & 0.162 & 0.162 & 0.193 & $0.000 *$ \\
\hline \multirow[t]{4}{*}{ \$ } & Conscientiousness: & 0.140 & 3.088 & 0.002 & 0.405 & 0.243 & 0.681 & $0.000 *$ \\
\hline & Meaningfulness $\ddagger$ & 0.365 & 7.475 & 0.000 & - & - & - & - \\
\hline & Safety & 0.062 & 1.472 & 0.142 & - & - & - & - \\
\hline & Availability: & 0.237 & 4.784 & 0.000 & - & - & - & - \\
\hline
\end{tabular}

Std, standardised; Sig, significant.

*, Significant change in the amount of variation of dependent variable being explained by the predictors.

$\dagger$, predictors: (constant), conscientiousness; $\$$, predictors: (constant), conscientiousness, meaningfulness, safety, availability.

TABLE 6: Hierarchical multiple regression analyses testing extraversion and psychological conditions constructs in the prediction of job engagement.

\begin{tabular}{|c|c|c|c|c|c|c|c|c|}
\hline \multirow[t]{2}{*}{ Model } & \multirow[t]{2}{*}{ Variable } & \multicolumn{3}{|c|}{$\begin{array}{l}\text { Dependent variable: Job engagement - Parameter } \\
\text { estimates }\end{array}$} & \multicolumn{4}{|c|}{ Model summary } \\
\hline & & Std. beta & $t$ & Sig. & $R^{2}$ & $R^{2} \Delta$ & Cohen's $f^{2}$ & Sig. $F \Delta$ \\
\hline$\dagger$ & Extraversion & 0.119 & 2.393 & 0.017 & 0.014 & 0.014 & 0.014 & $0.000 *$ \\
\hline \multirow[t]{4}{*}{ \$ } & Extraversion & 0.028 & 0.709 & 0.479 & 0.392 & 0.377 & 0.645 & $0.000 *$ \\
\hline & Meaningfulness & 0.390 & 8.028 & 0.000 & - & - & - & - \\
\hline & Safety & 0.098 & 2.400 & 0.017 & - & - & - & - \\
\hline & Availability & 0.266 & 5.412 & 0.000 & - & - & - & - \\
\hline
\end{tabular}

Std, standardised; Sig, significant.

*, Significant change in the amount of variation of dependent variable being explained by the predictors.

$\dagger$, predictors: (constant), conscientiousness; $\$$, predictors: (constant), conscientiousness, meaningfulness, safety, availability.

beta parameters reveal positive significant effect of psychological meaningfulness $\left(\beta_{2}=0.390\right)$, psychological safety $\left(\beta_{3}=0.098\right)$ and psychological availability $\left(\beta_{4}=0.266\right)$ on job engagement. Cohen's $f^{2}$ shows that the effect size measure for the final model indicates large effect on job engagement (Cohen's $f^{2}=0.645$ ). However, it should be noted that extraversion has no significant effect on job engagement in this final model $\left(\beta_{1}=0.028, t=0.709, p=0.479\right)$.

Table 7 shows that agreeableness as the only predictor variable for job engagement explains only $15.1 \%$ of the variation in the dependent variable $\left(R^{2}=0.151\right)$. From this model, the estimated beta parameters reveal positive significant effect of agreeableness $\left(\beta_{1}=0.389\right)$ on job engagement. Cohen's $f^{2}$ shows that the effect size measure for the agreeableness (Cohen's $f^{2}=0.178$ ) only model indicates medium effect on job engagement. Combined with psychological conditions, the resultant model accounted for a total of $40.3 \%$ of the variation in job engagement $\left(R^{2}=0.403\right)$. Thus, this model adds significant amount of variation in explaining job engagement to the agreeableness only model. This means adding psychological meaningfulness, psychological safety and psychological availability to agreeableness as predictor variables on job engagement results in a significant increase in the amount of variation explained by the model $\left(\Delta R^{2}=0.251\right.$, Sig $\Delta F=<0.0001)$. The estimated beta parameters reveal positive significant effect of agreeableness $\left(\beta_{1}=0.127\right)$, psychological meaningfulness $\left(\beta_{2}=0.370\right)$ and psychological availability $\left(\beta_{4}=0.237\right)$ on job engagement. Cohen's $f^{2}$ shows that the effect size measure for the final model indicates large effect on job engagement (Cohen's $f^{2}=0.675$ ). However, it should be noted that psychological safety has no significant effect on job engagement in this final model $\left(\beta_{3}=0.068, t=1.630\right.$, $p=0.104)$.

Table 8 shows that intellect as the only predictor variable for job engagement explains only $12.3 \%$ of the variation in the dependent variable $\left(R^{2}=0.123\right)$. From this model, the estimated beta parameters reveal positive significant effect of intellect $\left(\beta_{1}=0.351\right)$ on job engagement. Cohen's $f^{2}$ shows that the effect size measure for the intellect (Cohen's $f^{2}=0.140$ ) only model indicates medium effect on job engagement. Combined with psychological conditions, the resultant model accounted for a total of $39.5 \%$ of the variation in job engagement $\left(R^{2}=0.395\right)$. Thus, this model adds significant amount of variation in explaining job engagement to the intellect only model. This means adding psychological meaningfulness, psychological 
TABLE 7: Hierarchical multiple regression analyses testing agreeableness and psychological conditions constructs in the prediction of job engagement.

\begin{tabular}{|c|c|c|c|c|c|c|c|c|}
\hline \multirow[t]{2}{*}{ Model } & \multirow[t]{2}{*}{ Variable } & \multicolumn{3}{|c|}{$\begin{array}{c}\text { Dependent variable: Job engagement - Parameter } \\
\text { estimates }\end{array}$} & \multicolumn{4}{|c|}{ Model summary } \\
\hline & & Std. beta & $T$ & Sig & $R^{2}$ & $R^{2} \Delta$ & Cohen's $f^{2}$ & Sig. $\mathrm{F} \Delta$ \\
\hline$\dagger$ & Agreeableness & 0.389 & 8.458 & 0.000 & 0.151 & 0.151 & 0.178 & $0.000 *$ \\
\hline \multirow[t]{4}{*}{$\$$} & Agreeableness & 0.127 & 2.835 & 0.005 & 0.403 & 0.251 & 0.675 & $0.000 *$ \\
\hline & Meaningfulness & 0.370 & 7.599 & 0.000 & - & - & - & - \\
\hline & Safety & 0.068 & 1.630 & 0.104 & - & - & - & - \\
\hline & Availability & 0.237 & 4.748 & 0.000 & - & - & - & - \\
\hline
\end{tabular}

Std, standardised; Sig, significant.

*, Significant change in the amount of variation of dependent variable being explained by the predictors.

$\dagger$, predictors: (constant), agreeableness; $\downarrow$, predictors: (constant), agreeableness, meaningfulness, safety, availability.

TABLE 8: Hierarchical multiple regression analyses testing intellect and psychological conditions constructs in the prediction of job engagement.

\begin{tabular}{|c|c|c|c|c|c|c|c|c|}
\hline \multirow[t]{2}{*}{ Model } & \multirow[t]{2}{*}{ Variable } & \multicolumn{3}{|c|}{$\begin{array}{l}\text { Dependent variable: Job engagement - Parameter } \\
\text { estimates }\end{array}$} & \multicolumn{3}{|c|}{ Model summary } & \multirow[b]{2}{*}{ Sig. $F \Delta$} \\
\hline & & Std. beta & $T$ & Sig. & $R^{2}$ & $R^{2} \Delta$ & Cohen's $f^{2}$ & \\
\hline$\dagger$ & Intellect & 0.351 & 7.504 & 0.000 & 0.123 & 0.123 & 0.140 & $0.000 *$ \\
\hline \multirow{3}{*}{$\$$} & Meaningfulness & 0.369 & 7.315 & 0.000 & - & - & - & - \\
\hline & Safety & 0.097 & 2.391 & 0.017 & - & - & - & - \\
\hline & Availability & 0.253 & 5.099 & 0.000 & - & - & - & - \\
\hline
\end{tabular}

Std, standardised; Sig, significant.

*, Significant change in the amount of variation of dependent variable being explained by the predictors.

$\dagger$, predictors: (constant), intellect; $\$$, predictors: (constant), intellect, meaningfulness, safety, availability.

TABLE 9: Hierarchical multiple regression analyses testing neuroticism and psychological conditions constructs in the prediction of job engagement.

\begin{tabular}{|c|c|c|c|c|c|c|c|c|}
\hline \multirow[t]{2}{*}{ Model } & \multirow[t]{2}{*}{ Variable } & \multicolumn{3}{|c|}{$\begin{array}{l}\text { Dependent variable: Job engagement - Parameter } \\
\text { estimates }\end{array}$} & \multicolumn{4}{|c|}{ Model summary } \\
\hline & & Std. beta & $t$ & Sig. & $R^{2}$ & $R^{2} \Delta$ & Cohen's $f^{2}$ & Sig. $\mathbf{F} \Delta$ \\
\hline$\dagger$ & Neuroticism & -0.122 & -2.471 & 0.014 & 0.015 & 0.015 & 0.015 & $0.000 *$ \\
\hline \multirow[t]{4}{*}{ \$ } & Neuroticism & 0.037 & 0.831 & 0.406 & 0.392 & 0.377 & 0.645 & $0.000 *$ \\
\hline & Meaningfulness & 0.392 & 8.093 & 0.000 & - & - & - & - \\
\hline & Safety & 0.116 & 2.561 & 0.011 & - & - & - & - \\
\hline & Availability & 0.271 & 5.479 & 0.000 & - & - & - & - \\
\hline
\end{tabular}

Std, standardised; Sig, significant.

*, Significant change in the amount of variation of dependent variable being explained by the predictors.

$\dagger$, predictors: (constant), neuroticism; $\ddagger$, predictors: (constant), neuroticism, meaningfulness, safety, availability.

safety and psychological availability to intellect as predictor variables on job engagement results in a significant increase in the amount of variation explained by the model $\left(\Delta R^{2}=0.271\right.$, Sig $\Delta F=<0.0001)$. The estimated beta parameters reveal positive significant effect of psychological meaningfulness $\left(\beta_{2}=0.369\right)$, psychological safety $\left(\beta_{3}=0.097\right)$ and psychological availability $\left(\beta_{4}=0.253\right)$ on job engagement. Cohen's $f^{2}$ shows that the effect size measure for the final model indicates large effect on job engagement (Cohen's $f^{2}=0.653$ ). However, it should be noted that intellect has no significant effect on job engagement in this final model $\left(\beta_{1}=0.074, t=1.672, p=0.095\right)$.

Table 8 shows that neuroticism as the only predictor variable for job engagement explains only $1.50 \%$ of the variation in the dependent variable $\left(R^{2}=0.015\right)$. From this model, the estimated beta parameters reveal negative significant effect of neuroticism $\left(\beta_{1}=-0.122\right)$ on job engagement. Cohen's $f^{2}$ shows that the effect size measure for the neuroticism (Cohen's $f^{2}=0.015$ ) only model indicates small effect on job engagement. Combined with psychological conditions, the resultant model accounted for a total of $39.2 \%$ of the variation in job engagement $\left(R^{2}=0.392\right)$. Thus, this model adds significant amount of variation in explaining job engagement to the neuroticism only model. This means adding psychological meaningfulness, psychological safety and psychological availability to neuroticism as predictor variables on job engagement results in a significant increase in the amount of variation explained by the model $\left(\Delta R^{2}=0.377\right.$, Sig $\Delta F=<0.0001)$. The estimated beta parameters reveal positive significant effect of psychological meaningfulness $\left(\beta_{2}=0.392\right)$, psychological safety $\left(\beta_{3}=0.116\right)$ and psychological availability $\left(\beta_{4}=0.271\right)$ on job engagement. Cohen's $f^{2}$ shows that the effect size measure for the final model indicates large effect on job engagement (Cohen's $f^{2}=0.645$ ). However, it should be noted that neuroticism has no significant effect on job engagement in this final model $\left(\beta_{1}=0.037, t=0.831\right.$, $p=0.406)$.

\section{Ethical considerations}

The permission to conduct the research on the district municipalities was obtained from the municipal manager and the university ethics committee. The researcher ensured that all participants were informed wholly about the study and it was voluntary. Privacy, confidentiality, anonymity and dignity were upheld at all times. Ethical clearance number: MJO061SMHL01. 


\section{Discussion of results}

Extraversion, conscientiousness, intellect and agreeableness were found to be positively correlated with job engagement (Table 3). These results are consistent with the social exchange theory where employees who feel that their personality match with their job has increased job engagement than when they feel that their personality does not match their jobs. These study results are supporting the results of the studies carried out by Ramachandran and Pandit (2018) who found a positive correlation between job engagement and extraversion, conscientiousness, intellect and agreeableness traits. A lot of research have found a strong link between personality and work engagement $(\mathrm{Li}$, Wang, Gao, \& You, 2017) as one's personality is a key determinant of motivated behaviours when combined with and understood in the context of situational constraints and offerings, resulting in a behaviour set unique to everyone. On the other hand, neuroticism was found to be negatively correlated to job engagement, which is consistent with studies carried out by Nilforooshan and Salimi (2016) who also found a negative correlation between neuroticism and job engagement. This may be because people high in neuroticism are likely to be distracted and put more energy into worrying about personal issues that are irrelevant to the task at hand.

Job engagement was found to be positively correlated with psychological conditions (Table 4). Therefore, these results show that job engagement has a significant relationship with psychological conditions, which is consistent with the job demand resource model. This theoretical framework posits that having appropriate job resources, employees can enjoy higher levels of engagement, job satisfaction and low cynicism (Bakker \& Demerouti, 2007). In terms of psychological meaningfulness, as predicted by the relational model (Kahn \& Heaphy, 2014), it was found to be positively associated with job engagement. Kahn and Heaphy (2014) also pointed out that psychological availability reflects one's readiness or confidence to engage in a work role, given that individuals are also engaged in other activities. From the theoretical perspective, the results supports the job demand resource model, where employees become more obliged to their duties if sufficient resources are provided and the job becomes meaningful to them. In terms of psychological safety it also supports the job demand resource model, when the organisation provides an environment deemed by the employee to be psychologically safe, the employee will reciprocate with a willingness to engage.

Extraversion, conscientiousness, intellect and agreeableness were found to be positively correlated with all three psychological conditions whilst neuroticism was negatively correlated with psychological conditions (Table 5). The results are consistent with the findings found by Ongore (2014) and Frieder, Wang and Oh (2018) who found that individuals high in conscientious, extraversion, openness to experience perceive their work as more meaningful and as a result achieve heightened performance. Neuroticism was found to have a negative correlation with psychological conditions, which may be because individuals high in neuroticism are naturally wired to perceive their environment as less safe because of their naturally high level of anxiety and insecurity. Therefore, their natural inclination to be nervous, anxious would make them more apt to perceive their surroundings as unsafe to unwind in and be their true selves.

The study results also show that when personality traits are combined with psychological conditions there is a significant increase in the amount of variation explained by the independent variables on job engagement. Therefore, it can be noted that when personality is combined with psychological conditions it has more effect on job engagement.

\section{Theoretical implications}

This study contributes to a new framework on the relationship between job engagement, big five personality traits and psychological conditions. The present research adds to this knowledge base through its findings, which indicated that both personality and psychological conditions have a significant impact on job engagement.

The study provides an empirical support to Kahn (1990) in his formative qualitative work on employee engagement he identified psychological meaningfulness, psychological safety and psychological availability as necessary conditions of employee engagement. Therefore, the key implication of this study is the addition of depth to employee engagement theory by providing further empirical evidence in support of Kahn's (1990) findings. In addition, Frazier et al. (2017) identified the potential reciprocal relationship between employee engagement and psychological safety as an important, yet unanswered, question. This study provides an initial answer, thereby addressing a gap in the literature.

In addition, Jin and McDonald (2016) suggested that employee engagement in the public enterprises is a topic that remains under-researched as the operation of the public enterprise is different than that of the private sector. This study adds to the scholarly research by providing results related to employee engagement in an under-researched sector.

\section{Practical implications}

This study adds to an understanding of the influences of personality on work outcomes such as job engagement, giving areas for exploration of human resource practices based on personality assessment. Personality assessments should not be used on their own but it can be a good complement to other recruitment instruments. The study shows that when personality is combined with psychological conditions there is an increase in the amount of variation explained by the independent variables on job engagement. The implication of this results is that as organisation has no control over employee's personality they can focus more on 
psychological conditions they have control over to enhance engagement. Employees with different personalities can be engaged, provided facilitating conditions are available. The organisation should focus on creating awareness in supervisors about the skills they need to create an environment of psychological safety, ensure that proper resources are available for employees to perform in their roles and enable all supervisors to create environments in which their direct reports will find the work meaningful.

The link of psychological meaningfulness to work engagement indicates that organisations should attempt to foster meaningfulness by making employees feel that their work is worthwhile and valued and providing employees with a sense of value returned in exchange for effort invested in the work. In addition, managers should also work to establish employee perceptions of safety by developing supportive, trustworthy relations with their employees. Also, it is important that management practitioners regularly measure and track employee engagement within the workforce.

\section{Limitations and recommendations}

The quantitative approach to this study has implications for the research. The self-report questionnaires were used, and it is recommended that further studies use different methodologies, such as qualitative and quantitative, which could provide more in-depth insights into the relationship between personality traits and employee engagement. The study focused only on the six district municipalities hence more studies should be carried out in other sectors to allow for comparison. The study results also show that personality traits accounted for $16.2 \%$ (conscientiousness) of the variance in job engagement whilst psychological conditions accounted for $38.2 \%$, which means that there may be various other factors that affect employee engagement which leaves a scope for further research. The study also used convenience sampling, which might lead to biased results because of the reasons why some people choose to take part and some do not. Although this study used cross validation, future studies should use probability sampling techniques or a combination of both to ensure more generalisation. Another limitation of the study is that it did not investigate the mechanism through which engagement leads to performance as much literature alluded to that connection. A useful future study would be to control for different sources of variance to determine the unique contribution of engagement on performance.

\section{Conclusion}

The study focused on personality and psychological conditions to ascertain if they have an impact on job engagement. The question remains as to why employees, when working under comparable conditions display signs of job engagement whereas others display a few or no signs of job engagement (Wilson, 2009). We found that there is significant positive relationship amongst some of the big five personality traits, psychological conditions and job engagement. These findings help to shed light on factors that influence job engagement. It can be noted that psychological conditions accounted for higher job engagement than personality traits, which has an impact on the organisation as they have control over these conditions than an individual's personality. Organisation can play an important role by ensuring that employees' work is meaningful, enough resources and safety is available to enhance engagement. It is also important to acknowledge that both organisational variables and individual factors are constantly at play in influencing work engagement. The opportunity is for organisations to engage their employees more effectively by understanding their uniqueness' and differences. The opportunities for individuals is to flourish if they find personal meaning in work, have an emotional allegiance to work or discover their greater potential in the face of work challenges.

\section{Acknowledgements}

The authors would like to acknowledge the Eastern Cape province District Municipalities for their cooperation.

\section{Competing interests}

The authors declare that they have no financial or personal relationships that may have inappropriately influenced them in writing this research article.

\section{Authors' contributions}

T.S.M. is the main author of the article. The article was written from her PhD study. T.Q.M. was her supervisor, S.F.C. assisted with conceptual contributions and C.S.M. with data analysis.

\section{Funding information}

University of Fort Hare Govan Mbeki Research and Development Centre assisted through a three-year supervisory linked bursary.

\section{Data availability}

The authors confirm that the data supporting the findings of this study are available within the article.

\section{Disclaimer}

The data that support the findings of this study are available from the corresponding author, T.S.M., upon reasonable request.

\section{References}

Abu Khalifeh, A.N., \& Som, A.P.M. (2013). The antecedents affecting employee engagement and organisational performance. Asian Social Science, 9(7), 1-6. http://doi.org/10.5539/ass.v9n7p41

Akhtar, R., Boustani, L., Tsivrikos, D., \& Chamorro-Premuzic, T. (2015). The engageable personality: Personality and trait $\mathrm{El}$ as predictors of work engagement. Personality and Individual Differences, 73, 44-49. https://doi. org/10.1016/j.paid.2014.08.040

American Psychology Association. (2017). Personality. American Psychological Association. Retrieved from http://www.apa.org/topics/personality 
Aon Hewitt. (2018). Trends in global employee engagement. Aon Corporation. Retrieved from https://insights.humancapital.aon.com

Asiwe, D.N. (2014). The well-being of employees in a South African agricultura research organisation. Doctoral thesis. North-West University, Potchefstroom. Retrieved from http://dspace.nwu.ac.za/handle/10394/13088

Bailey, C., Madden, A., Alfes, K., \& Fletcher, L. (2017). The meaning, antecedents, and outcomes of employee engagement: A narrative synthesis. International Journal of Management Reviews, 19(1), 31-53. https://doi.org/10.1111/ijmr.12077

Bakker, A.B., \& Demerouti, E. (2007). The job demands - Resources model: State of the art. Journal of Managerial Psychology, 22(3), 309-328. https://doi.org/ 10.1108/02683940710733115

Bakker, A.B., \& Demerouti, E. (2017). Job demands - Resources theory: Taking stock and looking forward. Journal of Occupational Health Psychology, 22(3), 273-285. https://doi.org/10.1037/ocp0000056

Barreiro, C.A., \& Treglown, L. (2020). What makes an engaged employee: A facetlevel approach to trait emotional intelligence as a predictor of employee engagement. Individual Differences, 159, 109892. https://doi.org/10.1016/j. paid.2020.109892

Bayoumy, S.A. (2019). Relationship between job characteristics and work engagement among nursing staff. International Journal of Nursing Didactics, 9(1), 24-29. https://doi.org/10.15520/ijnd.v9i01.2406

Carter, W.R., Nesbit, P.L., Badham, R.J., Parker, S.K., \& Sung, L-K. (2018). The effects of employee engagement and self-efficacy on job performance: A longitudinal field study. The International Journal of Human Resource Management, 29(17), 2483-2502. https://doi.org/10.1080/09585192.2016.1244096

Chen, J., \& Nadkarni, S. (2017). It's about time! CEOs' temporal dispositions, temporal leadership, and corporate entrepreneurship. Administrative Science Quarterly, 62(1), 31-66. https://doi.org/10.1177/0001839216663504

Chikoko, G.L., Buitendach, J.H., \& Kanengoni, H. (2014). The psychological conditions that predict work engagement among tertiary education employees. Journal of Psychology in Africa, 24(6), 469-474. https://doi.org/10.1080/14330237.2014.99 7026

Choudhry, R.M., \& Zafar, B. (2017). Effects of skills, motivation, and personality traits on the competency of masons. International Journal of Sustainable Real Estate and Construction Economics, 1(1), 16-30. https://doi.org/10.1504/IJSRECE.2017. 10005277

Cohen, J. (1988). Statistical power analysis for the behavioral sciences (2nd edn.). Hillsdale, MI: Lawrence Erlbaum.

Cohen, J. (1992). A power primer. Psychological Bulleting, 112(1), 155-159. https:// doi.org/10.1037/0033-2909.112.1.155

Costa, P.T. Jr., \& McCrae, R.R. (1992). Revised NEO personality inventory (NEO PIR) and NEO five factor inventory (NEO-FFI): Professional manual. Odessa, FL: Psychological Assessment Resources.

Costantini, G., Richetin, J., Borsboom, D., Fried, E.I., Rhemtulla, M., \& Perugini, M (2015). Development of indirect measures of conscientiousness: Combining a facets approach and network analysis. European Journal of Personality, 29(5), 548-567. https://doi.org/10.1002/per.2014

Crabtree, S. (2013). Worldwide, $13 \%$ of employees are engaged at work. Retrieved from https://news.gallup.com/poll/165269/worldwide-employees-engagedwork.aspx

De Villiers, C. (2015). The relationships between emotional labour, the HEXACO personality traits, work engagement and burnout in the hospitality industry. Master's thesis. Stellenbosch: Stellenbosch University.

Deloitte Consulting. (2014). The global human capital trends report. Johannesburg: Deloitte Development LLC.

Demerouti, E., Bakker, A.B., De Jonge, J., Janssen, P.P.M., \& Schaufeli, W.B. (2001) Burnout and engagement at work as a function of demands and contact. Scandinavian Journal of Work Environment and Health, 27(4), 279-286. https:// doi.org/10.5271/sjweh.615

Eldor, L., \& Harpaz, I. (2016). A process model of employee engagement: The learning climate and its relationship with extra-role performance behaviours. Journal of Organisational Behaviour, 37(2), 213-235. https://doi.org/10.1002/ job.2037

Frazier, M.L., Fainshmidt, S., Klinger, R.L., Pezeshkan, A., \& Vracheva, V. (2017) Psychological safety: A meta-analytic review and extension. Personnel Psychology, 70(1), 113-165. https://doi.org/10.1111/peps.12183

Frieder, R.E., Wang, G., \& Oh, I.S. (2018). Linking job-relevant personality traits, transformational leadership, and job performance via perceived meaningfulness at work: A moderated mediation model. Journal of Applied Psychology, 103(3), 324-333. https://doi.org/10.1037/apl0000274

Goldberg, L.R. (1992). The development of markers for the big-five structure Psychological Assessment, 4(1), 26-42.

Goldberg, L.R. (1993). The structure of phenotypic personality traits. American Psychologist, 48, 26-34.

Goldberg, L.R., Johnson, J.A., Eber, H.W., Hogan, R., Ashton, M.C., Cloninger, C.R., \& Gough, H.G. (2006). The international personality item pool and the future of public-domain personality measures. Journal of Research in Personality, 40 84-96. https://doi.org/10.1016/j.jrp.2005.08.007
Gulamali, D.I. (2017). Relationship between personality and work engagement: The role of individual traits and international experience. Unpublished master's thesis. Porto: Universidade Católica Portuguesa.

Hakanen, J.J., Bakker, A.B., \& Schaufeli, W.B. (2006). Burnout and work engagement among teachers. Journal of School Psychology, 43(6), 495-513. https://doi. org/10.1016/j.jsp.2005.11.001

Hale, R. (2016). Towards a better understanding of employee engagement: Factors that explain employee engagement. Doctoral thesis. Minneapolis, MO: Capella University.

Handa, M., \& Gulati, A. (2014). Employee engagement does individual personality matter. Journal of Management Research, 14(1), 57-67.

IBM Corp. (2017). IBM SPSS statistics for windows. Armonk, NY: IBM Corp. Retrieved from https://hadoop.apache.org

Imam, A., \& Shafique, M. (2014). Impact of employee engagement in retaining employees through mediating effect of job satisfaction and organizational comploys through mediating effect of job satisfaction and organizational commitment and moderating effect of job stress: A corporate banking sector study
of Pakistan. Journal of Applied Environmental and Biological Sciences, 4(12), 1-15.

Jansriboot, P. (2016). Employee engagement of private sector employees in Southern Thailand: Personality, transformational leadership and psychological safety. DBA thesis. Kedah: Universiti Utara Malaysia.

Jin, M.H., \& McDonald, B. (2016). Understanding employee engagement in the public sector: The role of immediate supervisor, perceived organisational support, and learning opportunities. The American Review of Public Administration, 47(8), 881-897. https://doi.org/10.1177/0275074016643817

Judge, T., Higgins, C., Thoresen, C., \& Barrick, M. (1999). The big five personality traits, general metal ability, and career success across the life span. Personal Psychology, 52(3), 621-652. https://doi.org/10.1111/j.1744-6570.1999.tb00174.x

Kahn, W.A. (1990). Psychological conditions of personal engagement and disengagement at work. Academy of Management Journal, 33(4), 692-724. https://doi.org/10.5465/256287

Kahn, W.A., \& Heaphy, E.D. (2014). Relational context of personal engagement at work. In C. Truss, R. Delbridge, K. Alfes, A. Shantz, \& E. Soane (Eds.), Employee engagement in theory and practice (pp. 82-96). New York, NY: Routledge.

Lebowitz, S. (2016). The big 5 personality traits could predict who will and won't become a leader. Business Insider. Retrieved from http://www.businessinsider. com/

Li, M., Wang, Z., Gao, J., \& You, X. (2017). Proactive personality and job satisfaction: The mediating effects of self-efficacy and work engagement in teachers. Current Psychology: A Journal for Diverse Perspectives on Diverse Psychological Issues, 36(1), 48-55. https://doi.org/10.1007/s12144-015-9383-1

Lim, B., \& Ployhart, R.E. (2006). Assessing the convergent and discriminant validity of Goldberg's international personality item pool: A multi-trait multimethod examination. Organisational Research Methods, 9(1), 29-54. https://doi.org/ 10.1177/1094428105283193

Macey, W.H., \& Schneider, B. (2008). The meaning of employee engagement. Industrial and Organizational Psychology, 1(1), 3-30. https://doi.org/10.1111/ j.1754-9434.2007.0002.x

Mat, N., Jansriboot, P., \& Mat, N. (2019). Big five personality, transformational leadership, psychological safety, and employee engagement of private sector employees in Southern Thailand. Journal Pengurusan (UKM Journal of Management), 56. Retrieved from http://ejournal.ukm.my/pengurusan/article/ view/20543

Matebesi, S., \& Botes, L. (2017). Party identification and service delivery protests in the Eastern Cape and Northern Cape, South Africa. African Sociological Review, 21(2), 81-99.

May, D.R., Gilson, R.L., \& Harter, L.M. (2004). The psychological conditions of meaningfulness, safety, and availability and the engagement of the human spirit
at work. Journal of Occupational \& Organisational Psychology, 77(1), 11-37. https://doi.org/10.1348/096317904322915892

McCrae, R.R., \& John, O.P. (1992). An introduction to the five-factor model and its applications. Journal of Personality, 60(2), 175-215. https://doi.org/10.1111/ j.1467-6494.1992.tb00970.x

Moshoeu, A.N. (2017). A model of personality traits and work-life balance as determinants of employee engagement. Unpublished PhD dissertation. Pretoria: University of South Africa.

Mourino-Ruiz, E. (2017). The perfect human capital storm: Workplace human capita challenges and opportunities in the 21st century: Implication for organisation and leaders (2nd edn.). Charlotte, NC: Information Age Publishing.

Muizu, W.O.Z. (2017). The influence of personality on employee engagement and emotional intelligence (an empirical study on employees of rural banks in West Java, Indonesia). South East Asia Journal of Contemporary Business, Economics and Law, 12(2), 2289-1560.

Nienaber, H., \& Martins, N. (2016). Employee engagement in a South African context. Randburg: KR Publishing.

Nilforooshan, P., \& Salimi, S. (2016). Career adaptability as a mediator between personality and career engagement. Journal of Vocational Behaviour, 94, 1-10.

Njomo, L.M. (2019). A framework to enhance employee-manager relationship in South African municipalities - The case of the Nelson Mandela Bay municipality in Port Elizabeth, South Africa. Management Today, 9(2), 114-128.

Nunnally, J.C., \& Bernstein, I.H. (1994). Psychometric theory (3rd edn.). New York, NY: McGraw-Hill.

Olivier, A.L., \& Rothmann, S. (2007). Antecedents and consequences of work engagement in a multinational oil company. SA Journal of Industrial Psychology, 33(3), 49-56. https://doi.org/10.4102/sajip.v33i3.396 
Ongore, O. (2014). A study of relationship between personality traits and job engagement. Procedia - Social and Behavioural Sciences, 141, 1315-1319. https://doi.org/10.1016/j.sbspro.2014.05.226

Pocnet, C., Antonietti, J-P., Massoudi, K., Györkös, C., Becker, J., De Bruin, G.P., \& Rossier, J. (2015). Influence of individual characteristics on work engagement and job stress in a sample of national and foreign workers in Switzerland. Swiss Journal of Psychology, 74(1), 17-27. https://doi.org/10.1024/1421-0185/a000146

Public Display Technologies Report. (2014). South Africa's 1st state of employee engagement survey reveals management and communication failures. Retrieved from https://www.pdtsa.co.za/

Ramachandran, A., \& Pandit, A. (2018). Correlation between employee engagement and personality traits of five factor model. NCRD's Business Review: e-Journal, 3(1), 1-11.

Reddy, T. (2012). Psychometric properties of Goldberg's open-source big-five factor markers. Master's dissertation. Johannesburg: University of Johannesburg. Retrieved from https://ujcontent.uj.ac.za/vital/access/manager/Repository/ uj:35238?site_name=GlobalView

Rich, B.L. (2006). Job engagement: Construct validation and relationships with job satisfaction, job involvement, and intrinsic motivation. Unpublished doctora dissertation. Gainesville, FL: University of Florida.

Rich, B.L., Lepine, J.A., \& Crawford, E.R. (2010). Job engagement: Antecedents and effects on job performance. Academy of Management Journal, 53(3), 617-635. https://doi.org/10.5465/AMJ.2010.51468988

Rothmann, S. (2017). Employee engagement. In L.G. Oades, M. Steger, A. Delle-Fave, \& J. Passmore (Eds.), The Wiley-Blackwell handbook of the psychology of positivity and strengths-based approaches at work (pp. 317-341). Chichester: Wiley.

Rothmann, S., \& Baumann, S. (2014). Employee engagement: The effects of workhome/home-work interaction and psychological conditions. South African Journal of Economic and Management Sciences, 17(4), 515-530. https://doi.org/10.4102/ sajems.v17i4.419

Sahi, G.K., \& Mahajan, R. (2014). Employees' organisational commitment and its impact on their actual turnover behaviour through behavioural intentions. Asia Pacific Journal of Marketing and Logistics, 26(4), 621-646. https://doi. org/10.1108/APJML-01-2014-0015

Schaufeli, W.B. (2013). What is engagement? In C. Truss, K. Alfes, R. Delbridge, A Shantz, \& E. Soane (Eds.), Employee engagement in theory and practice. London: Routledge.
Schaufeli, W.B., Salanova, M., Gonzalez-Roma, V., \& Bakker, A.B. (2002). The measurement of engagement and burnout: A confirmatory factor analytic measurement of engagement and Journal of Happiness Studies, 3, 71-92. https://doi.org/10.1023/ approach. Journal

Schwartz, S.H. (2012). An overview of the Schwartz theory of basic values. Online Readings in Psychology and Culture, 2(1), 1-20. https://doi.org/10.9707/23070919.1116

Sekaran, U., \& Bougie, R. (2013). Research methods for business: A skill-building approach (6th edn.). New York, NY: Wiley.

Shkoler, O., \& Kimura, T. (2020). How does work motivation impact employees' investment at work and their job engagement? A moderated-moderation perspective through an international lens. Frontiers in Psychology 11, 38. https:// doi.org/10.3389/fpsyg.2020.00038

Shuck, B., \& Reio, G. (2013). Employee engagement and well-being: A moderation model and implications for practice. Journal of Leadership and Organisationa Studies, 21(1), 43-58. https://doi.org/10.1177/1548051813494240

Van den Berg, J.W., Mastenbroek, N.J.J.M., Scheepers, R.A., \& Jaarsma, A.D.C. (2017). Work engagement in health professions education. Medical Teacher, 39(11) 1110-1118. https://doi.org/10.1080/0142159X.2017.1359522

Viljevac, A., Cooper-Thomas, H.D., \& Saks, A.M. (2012). An investigation into the validity of two measure of work engagement. The International Journal of Human Resource Management, 23(17), 2642-3709.

Werner, A. (2014). Motivation. In P.S. Nel, \& A. Werner (Eds.), Human resource management (9th edn., pp. 264-288). Cape Town: Oxford University Press.

Wilson, K. (2009). A survey of employee engagement. Unpublished Doctor of Philosophy: Faculty of Graduate School. Columbia: University of Missouri.

Woods, S.A., \& Sofat, J.A. (2013). Personality and engagement at work: the mediating role of psychological meaningfulness. Journal of Applied Social Psychology, 43(11), 203-221.

Zehr, S.L. (2017). Safe to be engaged or engaged to be safe? A quantitative examination of the relationship between employee engagement and psychological safety within the federal workforce. Doctoral thesis. Sullivan University. Retrieved from scholarworks.sjsu.edu

Ziapour, A., \& Kianipour, N. (2015). A study of the relationship between characteristic traits and employee engagement (A case study of nurses across Kermanshah, Iran in 2015). Journal of Medicine and Life, 8(3), 134-140. 